\title{
Estradiol synthesis and action at the synapse: evidence for "synaptocrine" signaling
}

\author{
Luke Remage-Healey ${ }^{1 \dagger}$, Colin J. Saldanha ${ }^{2 \dagger}$ and Barney A. Schlinger ${ }^{3,4,5 *}$ \\ ${ }^{1}$ Neuroscience and Behavior Program, Center for Neuroendocrine Studies, University of Massachusetts, Amherst, MA, USA \\ 2 Department of Biology, The American University, Washington, DC, USA \\ ${ }^{3}$ Department of Integrative Biology and Physiology, University of California at Los Angeles, Los Angeles, CA, USA \\ ${ }^{4}$ Ecology and Evolutionary Biology, University of California at Los Angeles, Los Angeles, CA, USA \\ ${ }^{5}$ Laboratory for Neuroendocrinology, University of California at Los Angeles, Los Angeles, CA, USA
}

\section{Edited by:}

Kazuyoshi Tsutsui, Waseda University, Japan

\section{Reviewed by:}

Jacques Balthazart, University of Liege, Belgium

Suguru Kawato, University of Tokyo, Japan

\section{${ }^{*}$ Correspondence.}

Barney A. Schlinger, Department of Integrative Biology and Physiology and Ecology and Evolutionary Biology, University of California at Los Angeles, 621 Charles E Young Drive South, Los Angeles, CA 90095, USA e-mail: schlinge@lifesci.ucla.edu

${ }^{+}$Luke Remage-Healey and Colin J. Saldanha have contributed equally to the experiments and concepts described in this review.
Classically, the modulation of brain function and behavior by steroid hormones was linked exclusively to secretion by peripheral endocrine glands. Subsequently, steroid actions within the brain were shown dependent upon either synthesis and secretion by peripheral organs or by production within the CNS itself using peripheral sources of precursors. Discovery of the estrogen-synthetic enzyme aromatase in brain further bolstered the latter view and served as a catalyst for expanding concepts of neurosteroidogenesis. In parallel research, several steroids, including estradiol, were found to have rapid effects on neuronal excitability, partially explained by novel actions at neuronal membranes. Recent findings from multiple levels of analysis and labs necessitate an updated view on how steroids are delivered to neural circuits. There is now considerable evidence for expression of the aromatase enzyme within synaptic boutons in the vertebrate CNS. Furthermore, additional work now directly couples rapid regulation of neuroestrogen synthesis with neurophysiological and behavioral outcomes. In this review we summarize evidence for targeted and acute synaptic estrogen synthesis and perisynaptic estrogen actions in the CNS of songbirds. We evaluate these findings in the context of criteria associated with classic neuromodulatory signaling. We term this novel form of signaling "synaptocrine," and discuss its implications.

\section{INTRODUCTION}

As originally identified, neuronal and endocrine signaling were wholly independent forms of cell-cell communication. Indeed, it was only after an extended labor that birth was given to the more unified field of neuroendocrinology (Scharrer, 1954), in which identified neurons could synthesize and release hormones to affect both neural and endocrine outcomes. This dramatically transformed our appreciation of the chemical milieu within the vertebrate CNS. A largely separate body of research in the latter half of the twentieth century revealed an impressive array of chemicals released by synaptic terminals to influence the activity of nearby neurons. The criteria for what thus defines a "neurotransmitter" have been continually refined as new neuroactive molecules have been discovered. What began as a simple set of parameters that characterized the original neurotransmitter released at synaptic terminals (acetylcholine; Loewi, 1921), has now expanded to account for neurotransmission mediated by amino acids, monoamines, neuropeptides, metals, and some gases (Snyder, 2009). These disparate signaling molecules are now considered "neurotransmitters" by their common functional properties; they are synthesized in neurons, they are released at the synapse, they alter neuronal firing states, and they are rapidly inactivated following release. As the diversity of neural messengers and their associated timescales has grown, the distinction between molecules that mediate classical "neurotransmission" (i.e., fast, targeted excitation, or inhibition) and "neuromodulation" (slower, non-specific modulation) has become less clear (Katz, 1999).

Into this shifting landscape now stride the so-called neurosteroids, which can be synthesized by neurons and can exert exceedingly fast effects on neuronal excitability. The discovery that steroid hormones are synthesized in brain expanded traditional concepts of the brain as a mere target of steroids produced by peripheral organs. Current research is setting the stage for elaboration of a new set of concepts that regard steroids synthesized within the brain ("neurosteroids") as neuromodulators (Balthazart and Ball, 2006; Cornil, 2009; Saldanha et al., 2011). At present, while the synapse-specific steroid receptors as well as inactivation mechanisms are still being identified for neurosteroids, for the purposes of this review we will consider neurosteroid signaling as a candidate form of neuromodulation.

Because steroids are lipophilic molecules that can gain access to the brain via the circulation, some forms of neuromodulation can be relatively non-specific and accomplished by steroids produced anywhere in the body. These actions are viewed as classically "endocrine." Enhanced target specificity can be achieved 
when steroids are produced in close proximity to steroid-sensitive neural circuits, which can be viewed as classic "paracrine" actions. Modern methods have recently identified a more extreme case where steroids can be formed within presynaptic terminals for subsequent perisynaptic actions. This novel form of steroid production can be viewed as very highly targeted and specific. We and others have now applied the term "synaptocrine" to describe this highly specific form of neuromodulation, whereby a steroid is produced within synaptic boutons for direct perisynaptic actions (Saldanha et al., 2003; Mukai et al., 2006; Murakami et al., 2006).

Synaptocrine signaling differs from classical neurosecretion (Scharrer, 1954) in several fundamental ways. First, synaptocrine signaling involves the targeted and functional modulation of local hormone concentrations directly at the synapse. Second, as end-products of enzymatic reactions, synaptocrine steroid signals can be synthesized from substrates irrespective of the substrate source, be it peripheral endocrine glands, other brain regions, or even local production of precursor substrates at the synaptic terminal itself. Third, unlike most well-characterized perisynaptic neuromodulators, synaptocrine signals such as the lipophilic steroids cannot be packaged in vesicles, and hence the synaptocrine control of "release" is dependent upon steroidogenic enzyme activity.

What follows in this review is a consideration of the "synaptocrine hypothesis" in which we evaluate the categorization of estrogens secreted at synaptic terminals as bona fide neuromodulators. It is highly likely that many parallel synaptocrine signaling systems exist in the vertebrate CNS, such as those that synthesize $5 \alpha$ - or $5 \beta$-reduced $3 \alpha$-hydroxylated progestins for modulation of the $\mathrm{GABA}_{\mathrm{A}}$ receptor/ion channel complex (Majewska et al., 1986; Lan and Gee, 1994; Reddy, 2010). However, the best evidence for synaptocrine signaling comes from work focused on the synaptic production and action of estrogens. We therefore focus this review on the concepts generated from studies of neuroestrogen synthesis, fluctuation, and action. There is an extensive and growing literature on estrogen receptors on neuronal membranes, including on dendrites and somas where synaptically formed estradiol would act (Blaustein, 1992; Blaustein et al., 1992; McEwen and Alves, 1999; Milner et al., 2001; Beyer et al., 2003; Mitterling et al., 2010; Waters et al., 2011). Together, this body of work provides a strong impetus to consider neuromodulation by estradiol from any source, including synaptic terminals (see also Cornil, 2009). For a recent and in depth discussion of synaptocrine signaling see (Saldanha et al., 2011).

\section{CRITERIA FOR SYNAPTOCRINE SIGNALING AND FOR DEFINING ESTRADIOL AS A NEUROMODULATOR}

Neuromodulators intrinsic to the CNS have a well-defined set of properties. They are synthesized in neurons, released at the synapse, modulate neuronal firing states, and are rapidly inactivated following release. Based on this framework, for heuristic purposes we propose seven specific criteria to assess whether synaptocrine signaling adheres to the general principles of neuromodulation. These criteria are listed in Table 1 . We then address each of these criteria with a focus on evidence obtained from

\section{Table 1 | Criteria that define neuromodulation as applied to synaptocrine signaling.}

Criterion 1

Estrogens are lipophilic and cannot be stored, therefore synthesis and secretion are coupled. Aromatase, and potentially other steroidogenic enzymes, are therefore present in synaptic terminals to allow for synaptocrine signaling.

Criterion 2 To achieve targeted synaptocrine regulation of neuroestrogen levels, aromatase activity must be specifically and actively regulated at the synapse independent of its activity in other cellular compartments.

Criterion 3

At a rapid, neuromodulatory timescale, terminal release of estradiol is controlled by membrane depolarization linked to the opening of voltage-gated $\mathrm{Ca}^{++}$channels.

Criterion 4 Estradiol synthesis requires androgenic substrate that could arise from endocrine, paracrine, or autocrine sources. When estradiol is synthesized at the synapse a concomitant local decrease in the concentration of testosterone is predicted.

Criterion 5 Estradiol produced in synaptic terminals has either autocrine (presynaptic) or synaptocrine (post-synaptic) actions independent of estradiol produced elsewhere.

Criterion $6 \quad$ Modulation of neuronal activity by synaptic estradiol release produces changes in neural function and behavior independent of estradiol produced elsewhere.

Criterion 7 To preserve spatiotemporal resolution of neuromodulatory events, pre- and/or post-synaptic mechanisms exist to rapidly terminate the influence of estradiol. Following synaptic estradiol synthesis, release, and local action, mechanisms exist to rapidly quench estradiol concentrations within the synaptic cleft.

studies of neuroestrogen signaling, primarily drawn from studies in songbirds (see Box 1).

\section{CRITERION 1}

Estrogens are lipophilic and cannot be stored, therefore synthesis and secretion are coupled. Aromatase, and potentially other steroidogenic enzymes, are therefore present in synaptic terminals to allow for synaptocrine signaling.

\section{SYNAPTIC ESTRADIOL SYNTHESIS}

The ability to synthesize estradiol within neural tissues by the expression and activity of the $\mathrm{P}_{450}$ enzyme aromatase (CYP19a), is a highly conserved feature of the vertebrate brain (Naftolin et al., 1971, 1975; Callard et al., 1978) with enzyme activity typically measured in brain tissue homogenates (Callard, 1984; Balthazart, 1990; Lephart, 1996; Roselli and Resko, 2001; Simpson et al., 2002; London et al., 2009; Santen et al., 2009). Enzyme activity is present in discrete brain regions and corresponds with distribution patterns for aromatase protein identified by immunocytochemistry using aromatase-specific antibodies (e.g., Balthazart et al., 1990; Saldanha et al., 2000; Peterson et al., 2005) and usually, but, importantly, not invariably, with aromatase mRNA expression, as established by in situ hybridization procedures (Shen et al., 1994; Saldanha et al., 1998; Saldanha and Schlinger, 2008). 


\section{Box 1 | Songbirds as model organisms.}

Birds have served a crucial role in establishing the presence and function of aromatase in brain. The reproductive behavior of captive Japanese quail (Order Galliformes) and Ring-doves (Order Columbiformes) are well described and the role of androgens and estrogens in activating neural circuits controlling elements of masculine reproductive behaviors have been targets of intensive investigation (Adkins and Adler, 1972; Adkins Regan, 1981; Ball and Balthazart, 2002). For the most part, sex-steroids activate reproductive and aggressive behaviors by their actions on neural circuits in the hypothalamus/pre-optic area (HPOA), bNST, nucleus taenia of the ventromedial telencephalon and nucleus intercollicularis of the midbrain. Although this list of sex-steroid targets is not complete, these regions are the focus of most investigation.

Oscine songbirds (Order Passeriformes), differ from these model species in their capacity to learn some of their vocalizations, or songs, that can be extraordinarily complex forms of auditory communication produced by intricate and precise neural control of respiratory muscles and those of the syrinx, the avian vocal organ (Konishi et al., 1989). Song learning and precise motor control involves auditory processing and relays to an interconnected forebrain circuit that enables the learning and then production of their elaborate vocal repertoires. The nuclei that form the backbone of this circuitry express receptors for androgens and estrogens, making this song system an excellent platform for studies of steroid hormone action on cognition, behavior, neuroanatomy, and neuroplasticity (Bolhuis and Gahr, 2006; Mooney, 2009). In addition, many songbirds demonstrate remarkable spatial memory capabilities (Clayton, 2002). The songbird HP is a site of unusually high aromatase activity and estradiol enhances spatial memory function (Saldanha et al., 1998; Oberlander et al., 2004). Although we will touch on the songbird HP, for the remainder of this review, our focus will be on a subset of the song circuitry that includes the caudo-medial nidopallium (NCM), an auditory processing region, and nucleus HVC (proper name), a key nucleus that receives projections from the auditory system and, in turn, projects to learning and pre-motor centers required for appropriate song production (Mooney, 2009).
In the brains of endothermic vertebrates, aromatase is largely or exclusively neuronal e.g. (Canick et al., 1986), while neuroglia provide the predominant source of brain estrogens in some ectothermic vertebrates (Forlano et al., 2001, 2006). Although some glia express aromatase after neural injury in birds and mammals (Saldanha et al., 2009), typically neurons are the only cells immunostained in CNS tissue (Naftolin et al., 1996; Horvath et al., 1997; Saldanha et al., 2000). Staining is cytoplasmic, and is seen over somata and throughout processes (see also Wu et al., 2009). Under light-field microscopy, some aromatase immune-staining is punctate (Figure 1) and isolated from other immunostained cells (Saldanha et al., 2000; Peterson et al., 2005) as was first observed in quail brain (Foidart et al., 1994). As is the case for many cytochrome $\mathrm{P}_{450}$ enzymes, aromatase is membrane-bound being associated with endoplasmic reticulum (ER; Miller, 1988; Payne and Hales, 2004) that are widely distributed through the neuronal cytoplasm. Differential centrifugation of brain homogenates can produce microsomes (small circular bits of ER) that are highly enriched in aromatase relative to other subcellular fractions containing other organelles or byproducts of cellular disruption (Schlinger and Callard, 1989b).

\section{EVIDENCE FOR PRESYNAPTIC LOCALIZATION OF THE AROMATASE ENZYME}

When brain tissue is subject to careful differential centrifugation, nerve terminals pinch-off and reseal (synaptosomes) and can be isolated and purified for neurochemical analyses. Early evidence for the presynaptic localization of aromatase was obtained when activity could be detected in highly purified and chemically characterized synaptosomal preparations of the quail hypothalamus (Schlinger and Callard, 1989b). This synaptic localization of aromatase was later confirmed by immuno-electron microscopy (EM) studies of the brains of a variety of species including quail, rats, monkeys, and humans (Naftolin et al., 1996). The focus of these studies was on regions rich with aromatase somata and fibers, including the hypothalamus, bed nucleus of the stria terminalis
(bNST), and amygdala. In these regions, many aromatase-positive synaptic terminals were seen to make contact with aromatasepositive dendrites and somata. The functional implications of microsomal and synaptic estrogen synthesis, however, remained difficult to assess; the overlapping distributions of aromatase in both subcellular localizations made their specific contributions to neuroendocrine function difficult to study.

Aromatase can be detected in a variety of brain regions with some proportion of the overall aromatase protein present in presynaptic boutons (Schlinger and Callard, 1989b; Schlinger and Arnold, 1992b; Schlinger et al., 1992; Arnold and Schlinger, 1993; Naftolin et al., 1996; Hojo et al., 2004; Peterson et al., 2005; Rohmann et al., 2007). Indeed, the proportion of aromatase activity present in the microsomal fraction (presumably a measure of that aromatase in somata and in processes) as compared to that in the synaptosomal fraction can vary significantly. In some brain regions, a substantial fraction of the aromatase appears to reside in synapses that are spatially independent of aromatase somata. Such a conclusion is consistent with the view from immunocytochemical studies showing aromatase-positive terminals contacting aromatase-negative targets (Peterson et al., 2005) as well as some axons (up to several hundred micrometer long) that are seen to project elsewhere in brain where the post-synaptic targets are not obvious (Figure 1). In all likelihood, these aromatase-positive axons place aromatase-positive terminals onto distal unidentified neurons. If the target neuron is steroidsensitive, but lacks steroidogenic or steroid metabolic enzymes, then aromatase-positive neurons of one circuit could alter the steroidal-environment of another circuit by projecting afferents and forming synaptic contacts using terminals that contain steroid metabolic enzymes. It is this concept that forms the basis of the synaptocrine hypothesis.

It is important to point out that in addition to the presynaptic localization of aromatase described here, this enzyme has also been identified at post-synaptic loci (Naftolin et al., 1996). Indeed, in vitro studies have identified aromatase in dendritic spines of 

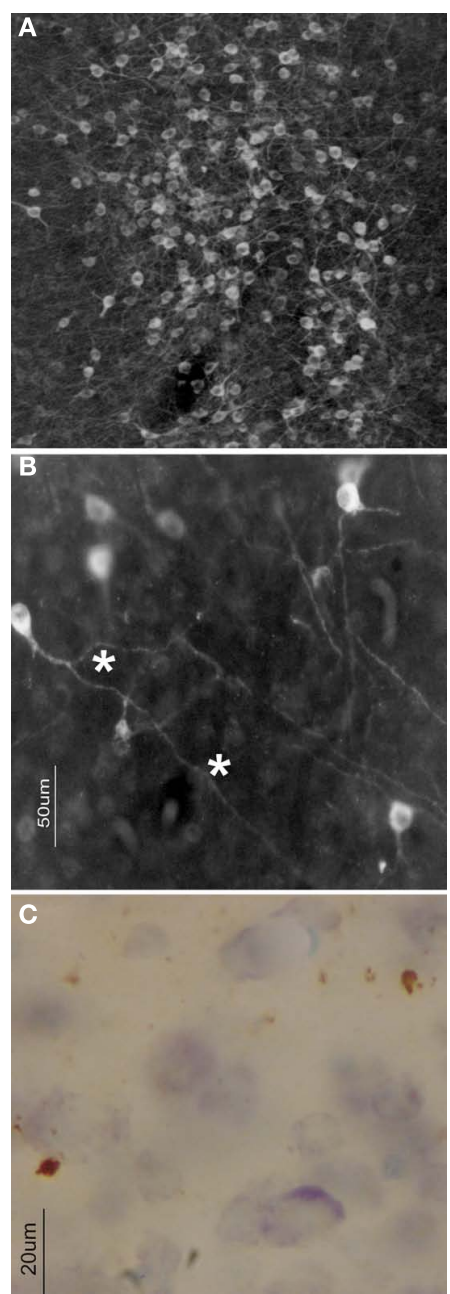

FIGURE 1 | In the zebra finch brain, several forebrain areas contain dense accumulations of aromatase-expressing neurons (A). At higher magnification (B), a substantive portion of the aromatase immunoreactivity is visible in fine fibers (asterisks) that extend a considerable distance from the cell body itself. Sometimes, as in HVC (C) puncta (asterisks) visible as brown deposits following aromatase ICC are clearly visible in an otherwise unstained nucleus (blue soma are Nissl stained cells).

mammalian brain (Kretz et al., 2004; Prange-Kiel and Rune, 2006), a location where the role of local aromatization is quite likely, tightly coupled to post-synaptic events. Additionally, the description of AR and ER at post-synaptic locations in rodent brain suggests that synaptic aromatization could have dramatic effects on post-synaptic, steroid-receptor-dependent mechanisms (Milner et al., 2001). Taken together, it seems probable that presynaptic and post-synaptic aromatization could have profound effects on synaptic transmission via presynaptic and post-synaptic steroid provision.

\section{NEUROSTEROIDOGENESIS}

The early identification of aromatase in brain was consistent with research showing that both androgens and estrogens could organize and/or activate some masculine neural circuits (Maclusky and
Naftolin, 1981; McEwen, 1981). Thus, aromatase in brain was seen as a terminal reaction of the full steroidogenic pathway (Miller, 1988; Payne and Hales, 2004) that was otherwise present in the testes. These studies prompted additional research that identified additional steroid metabolic enzymes in brain (Hutchison and Steimer, 1981; Martini, 1982). At about the same time, evidence began to accumulate indicating that steroids remained detectable in the brain despite removal of the gonads and adrenals, the known peripheral steroidogenic organs (Baulieu and Robel, 1990). These studies suggested the brain had the capacity to synthesize steroids de novo from cholesterol. Additional support for this concept of neurosteroidogenesis grew worldwide with the advent of increasingly sensitive methods to isolate steroids from other lipids, to confirm their identity and to quantify small concentrations, as well as the identification of the full suite of cholesterol transporters and enzymes required to fully synthesize steroids de novo e.g. (Compagnone et al., 1995a,b; King et al., 2002). The functional importance of this capacity for neurosteroidogenesis is still gaining traction. Nevertheless, its presence raises a crucial question that lies at the core of our perspective on steroid neuroendocrinology, namely how and when steroids are made available to the vast array of neural circuits when these lipophilic molecules have free access to the whole brain, can be produced peripherally or centrally and can be significantly modified in discrete neural circuits.

This latter set of questions gains additional conceptual significance when we consider that aromatase may not be the only sex-steroid metabolic enzyme to be compartmentalized in synaptic terminals. There is evidence for a presynaptic localization of the androgen-synthetic enzyme CYP17 in the mammalian hippocampus (HP; Hojo et al., 2004) as well as for $5 \beta$-reductase in the avian brain (Schlinger and Callard, 1989b). This latter enzyme both inactivates testosterone (Hutchison and Steimer, 1981) but also participates in the conversion of progesterone into $5 \beta$-allopregnanolone, a compound that strongly potentiates $\mathrm{GABA}_{\mathrm{A}}$-induced post-synaptic hyperpolarization (Carlisle et al., 1998) see also (Saldanha and Schlinger, 2008). Whether it inactivates androgens or synthesizes neuromodulatory progestins, the presence of $5 \beta$-reductase in synaptic terminals places it in a position to influence the local sex-steroid environment in a synaptocrine fashion.

\section{AROMATASE IN THE SONGBIRD BRAIN}

Relative to many other vertebrates, including other Orders of birds, aromatase is expressed at unusually high levels in the brains of songbirds (Vockel et al., 1990a,b; Schlinger and Arnold, 1991, 1992a; Schlinger et al., 1992; Shen et al., 1994, 1995; Balthazart et al., 1996; Saldanha and Schlinger, 1997; Soma et al., 1999, 2003; Saldanha et al., 2000; Silverin et al., 2000; Fusani et al., 2001; Riters et al., 2001; Saldanha and Coomaralingam, 2005). Aromatase is present not only in the phylogenetically conserved neural sites such as the hypothalamus, bNST, and the homolog of the mammalian amygdala, but also in large amounts in the telencephalon. Where aromatase immunoreactivity is seen in the songbird brain it is detected in somata and dendrites of neurons (Balthazart et al., 1996; Saldanha et al., 2000; Peterson et al., 2005). Moreover, in the zebra finch pre-optic area (HPOA), NCM, HP, and HVC, punctuate structures observed under light-microscopy are seen to 
be presynaptic boutons when examined using immuno-electron microscopy (Peterson et al., 2005).

Typically, biochemical measures of aromatase in brain reveals activity in synaptosomes with even greater enrichment in microsomes (Schlinger and Callard, 1989b; Roselli and Resko, 2001). In the zebra finch telencephalon, by contrast, aromatase is present in near equal amounts in synaptosomes and microsomes (Rohmann et al., 2007). Thus, approximately $50 \%$ of the total aromatase in the telencephalon is contained within presynaptic boutons underscoring the potential importance of synaptic estradiol provision in songbirds. These properties make zebra finches excellent animal models for understanding the functional importance of synaptic aromatization.

The presence of aromatase in synaptic terminals resolved some paradoxical early observations on aromatase in the songbird brain. First, aromatase activity was detected in the zebra finch HVC (Vockel et al., 1990b) but in situ hybridization showed little to no aromatase mRNA expression (Shen et al., 1995). Immunocytochemistry and immuno-electron microscopy resolved this paradox by detecting aromatase-positive terminals within HVC but an absence of aromatase-positive somata. The source of these terminals appeared to be aromatase-positive neurons whose somata lay outside of HVC (Saldanha et al., 2000). In a second case, aromatase activity and mRNA expression were both seen to be elevated in the songbird HP (Saldanha et al., 1998, 2004) but immunocytochemical studies showed few aromatase-positive somata that stained relatively weakly for aromatase (Saldanha et al., 2000). Closer inspection, including use of immuno-electron microscopy, identified an abundance of aromatase-positive presynaptic boutons in the dorsal HP where few aromatase-positive somata were found (Peterson et al., 2005). These terminals may arise from neurons located more ventrally that express aromatase mRNA but then transport aromatase protein down collaterals to terminals in the dorsal HP itself (Szekely and Krebs, 1996). Overall, these studies of both HVC and HP confirm predictions of the synaptocrine hypothesis that the steroidogenic enzyme aromatase is present in synapses and these synapses reside where other sources of aromatase are absent.

\section{CRITERION 2}

To achieve targeted synaptocrine regulation of neuroestrogen levels, aromatase activity must be specifically regulated at the synapse, independent of its activity in other cellular compartments.

\section{SEASONAL REGULATION OF AROMATASE}

It is widely observed among vertebrates that the enzyme aromatase, especially in the HPOA, is subject to dynamic regulation (Pasmanik et al., 1988; Balthazart, 1990; Roselli, 1991; Fusani et al., 2003) thereby providing adequate estradiol concentrations to activate masculine reproductive behavior (Pasmanik et al., 1988; Schlinger and Callard, 1989a; Roselli et al., 2003; Balthazart et al., 2004; Portillo et al., 2007; Wu et al., 2009). Exposure to photostimulatory long days to stimulate growth of the H-P-G axis disproportionately increases aromatase activity in microsomal (2.5-fold increase) and synaptosomal (sixfold increase) preparations of the Japanese quail HPOA (Schlinger and Callard, 1989b). This differential increase in synaptosomal enzyme could result from an increased number of aromatase-positive synapses, an increase in the concentration of aromatase in each synapse, or seasonal changes in the activity of the enzyme. Because central aromatization is required for activation of masculine reproductive behavior in this species (Ball and Balthazart, 2002), seasonal increases in synaptic aromatase may be crucial for providing the requisite amounts of bioactive estradiol.

\section{SEX-DIFFERENCES IN AROMATASE}

The zebra finch has become an important model in behavioral neuroendocrinology in part because males sing, but females do not (Immelman, 1969) and this sex dimorphism in behavior is reflected in a strikingly sexual dimorphic neural song system (Nottebohm and Arnold, 1976). The masculine neural song system is enlarged relative to that of females and estradiol likely plays a role in masculine development of the song circuitry (Gurney and Konishi, 1980; Simpson and Vicario, 1991; Grisham et al., 2008), in the masculine learning of song (Bottjer and Johnson, 1997), in the seasonal growth of song circuitry in seasonal breeders (Tramontin et al., 2003) and in activation of this circuitry when males sing (Meitzen et al., 2007). It is unlikely that estradiol is produced peripherally more so in male than in female zebra finches (Hutchison et al., 1984; Adkins-Regan et al., 1990; Schlinger and Arnold, 1991, 1992a) and no sexdifferences in gross brain aromatase activity, or mRNA expression have been measured (Vockel et al., 1990b; Schlinger and Arnold, 1992b; Shen et al., 1995; Wade et al., 1995). However, upon finer examination, when aromatase in fibers is considered independently from that in somata, reliable seasonal regulation and male-biased sex-differences and have been detected. Schlinger and Callard (1989b) first reported that upon exposure to long days, while microsomal (somal and dendritic) aromatase increased 2.5-fold, that in synaptosomes (axonal) increased five to sixfold. Indeed, techniques as diverse as light-microscopy that compare immunoreactive fibers to soma, immune-electron microscopy, Western blotting on subcellular fractions, and biochemical enzyme activity on sub-fractions all reveal that adult male zebra finches possess more aromatase in synaptosomes or synaptic terminals relative to adult females (Saldanha et al., 2000; Peterson et al., 2005; Rohmann et al., 2007) pointing to sexspecific regulation of presynaptic synthesis of estradiol. More specifically while no part of the zebra finch brain appears to be sexually dimorphic in the number or intensity of cell bodies that express aromatase transcript or protein (Shen et al., 1995; Saldanha et al., 2000), the number of immunoreactive fibers is higher in males relative to females in the HPOA and NCM (Saldanha et al., 2000). Further studies using electron microscopy and direct observation of immunoreactive presynaptic boutons and terminals supported these data and showed that males had more aromatase-expressing synapses than did females (Peterson et al., 2005), supporting the concept that synaptocrine, and not paracrine, may be a better explanation of the dramatic and sexually dimorphic estrogen dependence of the zebra finch brain and behavior.

The results of these ultrastructural analyses were supported by studies that measured the aromatase activity of subcellular fractions of the zebra finch brain. In homogenates of whole 
telencephalon, no sex-differences have been reported (Schlinger and Arnold, 1992b). However, once the brain is separated into microsomes and synaptosomes, whereas measures of aromatase in microsomes prepared from the adult telencephalon continue to be similar in males and females, synaptosomal preparations of the male telencephalon had significantly higher levels of aromatase activity than did similar preparations of the female (Rohmann et al., 2007). Interestingly, the sex dimorphism was only evident in the posterior forebrain, a region that is more abundant in aromatase relative to the anterior forebrain (Shen et al., 1995; Saldanha et al., 2000) and a region where many estrogen-dependent targets such as song nuclei are located (Nottebohm et al., 1976). It is unclear, at this point, why sex-dimorphisms in synaptosomal aromatase are only detectable in the posterior telencephalon, however, measures of aromatase activity in purified sub-fractions echoes the patterns observed in ultrastructural studies that have used direct observation of aromatase-immunoproduct in synaptic profiles (Peterson et al., 2005).

\section{SYNAPTIC AROMATASE AND SONG PRODUCTION}

The recently observed sex-differences presynaptic aromatase expression suggest a relationship between presynaptic estradiol synthesis and male-typical song behavior (Rohmann et al., 2007). Additional evidence for such a relationship comes from two sources. First, whereas aromatase is usually enriched in microsomal sub-fractions from brain (Schlinger and Callard, 1989b), in the zebra finch forebrain (containing much of the song control circuitry) approximately one half of the overall aromatase activity is contained in synaptosomes (Rohmann et al., 2007). Second, and perhaps more importantly, aromatase-positive synaptic boutons enshroud "song system" nuclei in the caudal forebrain (Saldanha et al., 2000; Peterson et al., 2005; London et al., 2009). These observations stimulated experiments to determine if there was indeed a relationship between synaptic aromatase and singing behavior itself.

Indeed, aromatase activity is elevated more than twofold in males that sing for $30 \mathrm{~min}$ relative to males that do not sing for an equivalent period, when the forebrain is rapidly dissected and assayed for activity of the aromatase enzyme (Remage-Healey et al., 2009). Aromatase upregulation is specifically localized to the synaptosomal fraction within the posterior telencephalon (Remage-Healey et al., 2009), and is not evident in the microsomal fraction, indicating a cell-compartment specific regulation of aromatase within synaptosomes. Courtship singing therefore involves an upregulation of aromatase activity specifically in synaptic terminals, although it is unclear whether this depends on rapid phosphorylation events (see below) or longer-term, constitutive upregulation of terminal aromatase. These experiments provide evidence that songbirds have the capacity to regulate aromatase in synaptic terminals independent of somal aromatase in a behaviorally relevant context.

\section{CRITERION 3}

At a rapid, neuromodulatory timescale, terminal release of estradiol is controlled by neuronal depolarization linked to the conductance of presynaptic voltage-gated $\mathrm{Ca}^{++}$channels.

\section{RAPID REGULATION OF NEURONAL AROMATASE}

Estrogens have long been known to exert rapid actions (seconds to minutes) on peripheral tissues (Szego and Davis, 1967) and within the brain itself (McEwen and Alves, 1999). Many of the acute actions of estrogens on neuronal activity occur in a timeframe that is far too fast to involve the classical regulation of gene expression via nuclear receptors (Mermelstein et al., 1996; Woolley, 2007; Micevych and Mermelstein, 2008). Experiments that have examined the enzymatic activity of aromatase itself have shown that the capacity for estrogen production in brain can change in a minute-by-minute timeframe. The aromatase protein in the quail hypothalamus is sensitive to $\mathrm{Ca}^{++}$-dependent phosphorylation events which can cause abrupt decreases in its activity (Balthazart et al., 2001, 2003, 2005). Importantly, treatments that increase excitability within quail hypothalamic explants (i.e., elevated $\mathrm{K}^{+}$ions, or glutamate agonists) similarly cause a rapid decrease in aromatase activity (Balthazart et al., 2001). These results have established a model in which neuronal aromatase is phosphorylated upon excitation, locally reducing a neuron's capacity to synthesize estrogen.

In vivo microdialysis experiments in zebra finches described below have taken a similar pharmacological approach down to the level of presynaptic terminals. These studies begin to address the question of whether $\mathrm{Ca}^{++}$dependent events within presynaptic terminals enable the precise control of neuroestrogen delivery to specific perisynaptic targets.

\section{MEASUREMENT OF LOCAL ESTROGENS IN VIVO}

If aromatase activity changes within synaptic terminals in the songbird forebrain, the synaptocrine hypothesis proposes that estrogenic end-products are immediately released and result in altered levels of estrogens at or near the synapse. In other words, local levels of neuroestrogens near synaptocrine terminals should fluctuate relative to surrounding extracellular cerebro-spinal fluid (CSF). The recent development of in vivo steroid microdialysis, in awake, behaving songbirds provides an opportunity to study putative synaptocrine events (RemageHealey et al., 2008). The methods for microdialysis have been extensively validated and described elsewhere (RemageHealey et al., 2008, 2010b). Below we describe recent experiments that specifically address synaptocrinology using microdialysis. Despite spatial and temporal precision of microdialysis, the technology is unable to resolve individual synaptocrine events, per se. Even so, as described above, synaptosomal aromatase accounts for a large quantity of the total aromatase in the caudal forebrain of adult male zebra finches (Rohmann et al., 2007). Therefore, acute fluctuations in local estrogens within the caudal forebrain captured using in vivo microdialysis likely reflect, in part, the integration of synaptocrine events.

\section{CHANGES IN NEUROESTROGENS DURING NEUROTRANSMITTER ACTIVATION}

In both the hypothalamus and hippocampus, in vitro aromatase activity, and estrogen production are under rapid control by glutamatergic agonists and antagonists, likely via $\mathrm{Ca}^{++}$-dependent 
phosphorylation of aromatase itself (Balthazart et al., 2003, 2005, 2006; Hojo et al., 2008). In vivo microdialysis experiments in the zebra finch forebrain showed that neuroestrogen levels were rapidly suppressed by local infusion of glutamate $(30 \mathrm{~min})$, and unchanged during similar treatment with NMDA and GABA (Remage-Healey et al., 2008). Thus, neurotransmitters are able to drive changes in aromatase activity and neuroestrogen levels in three separate model systems and preparations (quail hypothalamus, rat hippocampus, and zebra finch cortex). However, the degree to which these phenomena depend on synaptocrine events had not been directly assessed with these methods.

More recent in vivo microdialysis experiments have targeted presynaptic voltage-gated calcium channels (VGCCs), and the results have shed light on the role of electrochemical control of neuroestrogen levels at the synapse. A series of experiments in zebra finch cortex showed that neuroestrogen levels were: (1) rapidly suppressed by 30 -min of infusion of elevated $\mathrm{K}^{+}$ions, and (2) significantly elevated following 90-min of local $\mathrm{Ca}^{++}$ion removal, as measured by in vivo microdialysis (Remage-Healey et al., 2011). Therefore, similar to the effects of excitatory glutamate, $\mathrm{K}^{+}$-induced depolarization suppresses neuroestrogens, while removing extracellular $\mathrm{Ca}^{++}$causes neuroestrogen levels to accumulate over time. Both of these findings are consistent with an excitatory, $\mathrm{Ca}^{++}$-dependent regulation of aromatase activity seen in quail (Balthazart et al., 2006). A critical test of this model incorporated retrodialysis of the specific presynaptic VGCC blocker omega conotoxin. In the presence of conotoxin, the suppressive effects of $\mathrm{K}^{+}$-induced depolarization on neuroestrogen levels is blocked. Together, this evidence indicates that the neuroestrogen levels in zebra finch cortex in vivo are controlled by electrochemical events that occur within presynaptic terminals. These findings directly establish a synaptocrine source for a component of neuroestrogens detected via microdialysis technology.

Taken together, the recent observations from quail hypothalamus and zebra finch auditory cortex suggest a common mechanism for the control of estrogen production within the CNS, namely via excitatory $\mathrm{Ca}^{++}$dependent changes in local aromatase activity. These observations raise the question as to whether endogenous activation of neural circuits regulate the local fluctuations in neuroestrogens.

\section{CHANGES IN NEUROESTROGENS IN VIVO DURING BEHAVIOR}

The validation of in vivo microdialysis for neurosteroids has allowed for the examination of acute changes within the forebrain of the zebra finch that might reflect rapid changes in synaptocrine synthesis. The focus of these experiments has been on the NCM, an auditory cortical nucleus that is enriched in synaptosomal aromatase (Peterson et al., 2005; Rohmann et al., 2007). When males are exposed to females and actively courting and singing, microdialysis within NCM reveals that neuroestrogen levels are acutely elevated during $30 \mathrm{~min}$ behavioral trials relative to baseline conditions (Remage-Healey et al., 2008). These changes appear to be specific to NCM; when probes are targeted to anterior forebrain (containing very little synaptosomal or somal aromatase) local estrogens remain unchanged. A similar acute rise in $17 \beta$-estradiol within NCM also occurs when males are exposed to conspecific songs, but not control white noise sounds, indicating that auditory processing of song stimuli alone can drive fast changes in brain steroid levels. Importantly, circulating levels of both $17 \beta$-estradiol and testosterone are not responsive to these same manipulations. Together, these findings reveal an extremely localized flux in neuroestrogens within a discrete region of auditory cortex that occurs during changes in socially relevant behavior.

\section{CRITERION 4}

Estradiol synthesis requires androgenic substrate that could arise from endocrine, paracrine, or autocrine sources. When estradiol is synthesized at the synapse a concomitant local decrease in the concentration of testosterone is predicted.

\section{SOURCE OF ANDROGEN SUBSTRATE FOR NEUROESTROGEN SYNTHESIS}

A feature of synaptocrine signaling that serves to distinguish it as a form of neuromodulation is that the androgenic precursors for synaptic aromatization can be derived from several sources including peripheral endocrine delivery, paracrine delivery from nearby neuronal or glial sources or autocrine delivery with androgen synthesized in the synaptocrine cell itself. It is not yet clear whether aromatase-positive cells per se synthesize androgens or any other upstream precursors in the zebra finch brain. Nevertheless, we and others have documented expression in the zebra finch brain of all of the fundamental enzymes and transporters of the steroidogenic pathway including the steroidogenic acute regulatory protein (StAR) and transporter protein (TSPO) that transport cholesterol into specialized mitochondria, as well as the steroidogenic enzymes, side-chain cleavage (SCC), 3 $\beta$-HSD, and CYP17 (London et al., 2003, 2006, 2009, 2010; London and Schlinger, 2007). Thus, in addition to peripheral steroidogenesis, songbirds appear to have the ability to synthesize steroids in brain. This leaves open the possibility for endocrine, paracrine, or autocrine provision of androgens to the aromatase in synaptic boutons.

Whereas testosterone is the immediate substrate for synaptic synthesis of estradiol, it is possible that testosterone itself is produced in brain from endocrine delivery of substrates. The enzyme $3 \beta-H S D$ converts pregnenolone to progesterone as well as the androgen precursor dehydroepiandrosterone (DHEA) to androstenedione. This latter hormone is itself a substrate for aromatization, but it can also be converted into testosterone by $17 \beta-$ HSD into testosterone. Both $3 \beta-H S D$ and $17 \beta-H S D$ are expressed and active in the songbird brain and have been shown to function coordinately with aromatase to convert the androgen precursor dehydroepiandrosterone (DHEA) into estradiol in the songbird brain (Vanson et al., 1996; Tam and Schlinger, 2007; London et al., 2010). DHEA has been shown to activate some masculine behaviors in songbirds, including during the non-breeding season when the gonads are regressed and likely producing little or no androgen (Soma and Wingfield, 2001; Soma et al., 2002). The enzyme $3 \beta-H S D$ is upregulated in several brain regions during the non-breeding season as compared to the breeding season (Pradhan et al., 2010) supporting a mechanism to convert DHEA into estradiol to activate non-breeding aggressive behaviors. Importantly, as we have seen for aromatase, $3 \beta-\mathrm{HSD}$ activity is subject to relatively rapid regulation (within $30 \mathrm{~min}$ ) during behavioral 
encounters (Pradhan et al., 2010). Together with data collected using in vivo microdialysis of estradiol, these data argue that rapid regulation is an attribute of at least some steroidogenic enzymes in brain enabling locally synthesized steroids to participate in rapid neuromodulation.

Evidence for the use of local substrates in synaptic aromatization comes from simultaneous measures of testosterone and estradiol in vivo using microdialysis (Remage-Healey et al., 2008). When the aromatase inhibitor Fadrozole is retrodialyzed into the NCM of awake male zebra finches, local levels of $17 \beta$-estradiol are suppressed. At the same time, local testosterone levels are significantly elevated during Fadrozole treatment, consistent with an accumulation of androgen precursors following aromatase inhibition (see Remage-Healey et al., 2008). Similar inverse changes in dialysate levels of testosterone and estradiol have been detected in male zebra finches during exposure to specific behavioral contexts. These results are consistent with the hypothesis that neural aromatization relies on local provision of androgenic substrate that is not continuously refreshed from the systemic circulation or local synthesis. Additional evidence for direct regulation of testosterone levels in the zebra finch NCM by retrodialysis of GABA (Remage-Healey et al., 2008) supports the conclusion that there are endogenous mechanisms in brain to regulate local androgen concentrations.

\section{CRITERION 5}

Estradiol produced in synaptic terminals has either autocrine (presynaptic) or synaptocrine (post-synaptic) actions independent of estradiol produced elsewhere.

If synaptocrine secretion of steroids is to carry information in the manner of other, traditional neural messengers, there should be observable effects on pre- and/or post-synaptic neuronal properties. The most likely scenario is via changes in neuronal firing patterns within the synaptocrine circuit. We and others have taken advantage of the clearly identified role of the zebra finch auditory NCM in processing song and other auditory signals to test for a modulatory influence of locally synthesized estrogens.

\section{LOCALLY DERIVED ESTROGENS: ELECTROPHYSIOLOGY AND AUDITORY PROCESSING}

Microdialysis was recently coupled to extracellular electrophysiology recordings in the NCM. This combined approach allows precise regulation of local neurosteroid levels via reverse microdialysis for drug delivery and washout alongside concomitant recordings of multi- and single-unit activity. This approach demonstrated that locally derived estrogens rapidly boost the auditory-evoked unit activity of NCM neurons within $30 \mathrm{~min}$ (Remage-Healey et al., 2010a). Exogenous treatment with 17ß-estradiol caused $50 \%$ increases in the firing frequency of auditory neurons, relative to the previous $30 \mathrm{~min}$ of vehicle delivery. Close inspection of the firing patterns revealed that $17 \beta$-estradiol caused significant increases in the occurrence of "bursts" of single-unit activity, and acute aromatase blockade with the drug fadrozole caused a rapid suppression of bursting, consistent with a role for local, endogenous neuroestrogens in modulating firing properties of auditory neurons.
These findings were independently replicated in the lab of Pinaud and Tremere. Extracellular recordings from a bilateral multielectrode array in NCM were coupled with pressure injection of either vehicle, estradiol or an aromatase inhibitor adjacent to an electrode. Estradiol rapidly boosted auditory-evoked firing rates, while the aromatase inhibitor ATD suppressed them (Tremere et al., 2009). Further, in vitro patch recordings showed that $17 \beta$ estradiol exerts rapid suppression of GABAergic currents (miniature inhibitory post-synaptic currents, mISPCs) in NCM slices via presynaptic modulation. More recently this group showed that the neural discrimination of auditory signals is enhanced by locally produced estrogens (Tremere and Pinaud, 2011). Together, these independent and convergent findings provide convincing evidence that estrogens produced in the NCM can exert rapid actions on the patterning of NCM auditory neurons.

Additional support for the neuromodulatory actions of estrogens in the NCM come from recent unpublished experiments. A conjugated form of estradiol that does not diffuse through cell membranes was delivered via retrodialysis in the same manner as estradiol in the electrophysiology experiment above. Conjugated estradiol exerted similarly rapid actions as unconjugated $17 \beta$-estradiol on the auditory-evoked activity of NCM neurons (Remage-Healey and Schlinger, unpublished). Thus, neuroestrogens appear to mediate some or all of their rapid actions via a membrane-bound receptor in the songbird brain. The exact receptor mechanism for these membrane effects is unclear, although recent evidence indicates that estradiol can act on GABAergic currents in vitro in NCM slice preparations (Tremere et al., 2009). Thus, rapid actions of estrogens in the songbird may occur via a membrane receptor that is coupled to this or a similar rapid mechanism. Moreover, extranuclear/membrane expression of estrogen receptors is common among vertebrates (Milner et al., 2001; Beyer et al., 2003; Montague et al., 2008; Mitterling et al., 2010), and the rapid actions of estrogens in songbirds may involve one of the many "non-classical" modes of estrogen action identified to date, notably a variety of signaling cascades (Woolley, 2007; Meitzen and Mermelstein, 2011; Moenter and Chu, 2011; Roepke et al., 2011). The mechanism for postsynaptic estrogen action in the zebra finch auditory system remains unknown.

\section{CRITERION 6}

Modulation of neuronal activity by synaptic estradiol release produces changes in neural function and behavior independent of estradiol produced elsewhere.

\section{MODULATION OF BEHAVIOR}

If estrogens are produced in a circuit via synaptocrine mechanisms, and subsequently exert intrinsic modulation of that circuit, what functional consequences does this have for an animal's behavior? Because in vivo microdialysis has been optimized for awake, behaving birds, the same technology used for studying synaptocrine fluctuations and neurophysiological events can therefore also be applied to the study of behavioral modulation in zebra finches.

Adult zebra finches express behavioral preferences in the laboratory for familiar songs. Recent microdialysis experiments 
showed that disrupting the normal production of neuroestrogens in the NCM with fadrozole (using the same dose as in the electrophysiology and microdialysis experiments above) caused a rapid (within $30 \mathrm{~min}$ ) suppression of behavioral song preference. When the fadrozole was washed out with normal aCSF over $30 \mathrm{~min}$, the song preference of individuals for a familiar song was restored to control levels (Remage-Healey et al., 2010a). Interestingly, this drop in preference was only observed when fadrozole was delivered to the left hemisphere NCM and not the right hemisphere NCM, indicating a laterality for endogenous neuroestrogen actions in support of song preference, and possibly a laterality in function for left vs. right NCM. To our knowledge, fadrozole is equally potent at blocking aromatase activity in all cellular compartments, so it is currently unknown to what extent the results of this behavioral experiment depend on synaptocrine vs. somal neuroestrogen production. Similar to the emergent electrophysiology results, recent experiments have provided independent confirmation of the suppressive effects of aromatase inhibition and estrogen receptor blockade on song preference in NCM, using intracranial cannula injections (Tremere and Pinaud, 2011).

As presented above, the songbird forebrain contains abundant expression of the steroidogenic enzyme $5 \beta$-reductase (Vockel et al., 1990b; Schlinger et al., 1995). Similar to the actions of aromatase, this enzyme converts androgens and progestins into their $5 \beta$-reduced metabolite counterparts. While the rapid effects of estradiol on songbird auditory physiology are clear, $5 \beta$-reduced androgens do not produce significant changes in NCM firing properties (Remage-Healey et al., 2010a). Therefore, local, possibly synaptic, aromatase activity is critical for boosting auditory responsiveness in NCM and guiding song preference (RemageHealey et al., 2010a), while the predominant $5 \beta$-reduced androgen, $5 \beta$-dihydrotestosterone, is naturally synthesized in part via synaptocrine actions but has no effect on the excitability of auditory neurons in NCM (for similar findings see also Tremere and Pinaud, 2011). These observations suggest that synaptocrine actions of steroids are "specialized" in a similar way as other neuromodulators at the synaptic level for local modulatory events. To date, a direct, physiological role for $5 \beta$-reductase in synaptic terminals has not yet been identified, although $5 \beta$-reduced steroids can allosterically modulate the $\mathrm{GABA}_{\mathrm{A}}$ receptor in cultured zebra finch neurons (Carlisle et al., 1998). Given their potency and potential for synaptocrine actions, further analysis of $5 \beta$-reduced steroid actions on adult songbird neurons will be a fruitful avenue for research.

\section{CRITERION 7}

To preserve spatiotemporal resolution of neuromodulatory events, pre- and/or post-synaptic mechanisms exist to rapidly terminate the influence of estradiol. Following synaptic estradiol synthesis, release, and local action, mechanisms exist to rapidly quench estradiol concentrations within the synaptic cleft.

All neuromodulatory systems possess a mechanism for inactivation. These mechanisms preserve the fidelity of the spatial and temporal information transmitted by the neuromodulator,

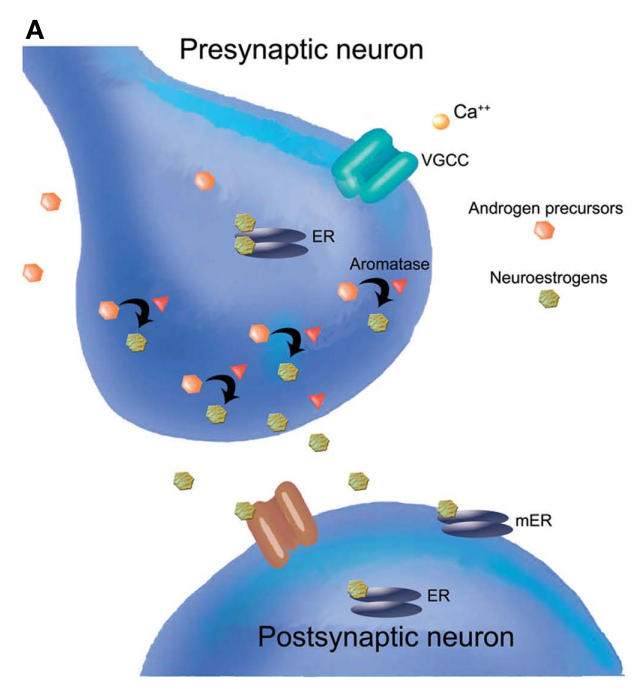

FIGURE 2 | Synaptocrine signaling: androgenic precursors (orange hexagons) from the extracellular space, adjacent cells such as astroglia, or within individual neurons are available as substrates for the enzyme aromatase (red triangles) located within presynaptic boutons. Estrogens (green hexagons) synthesized within the presynaptic bouton are then available to bind presynaptic ERs (gray ovals) and modulate the dynamics of presynaptic neurotransmitter release. Synaptocrine estrogens may also diffuse into the synaptic cleft and thereby interact with post-synaptic ion channel receptors (brown channel), and/or post-synaptic ERs (gray ovals, cytosolic) or membrane ERs

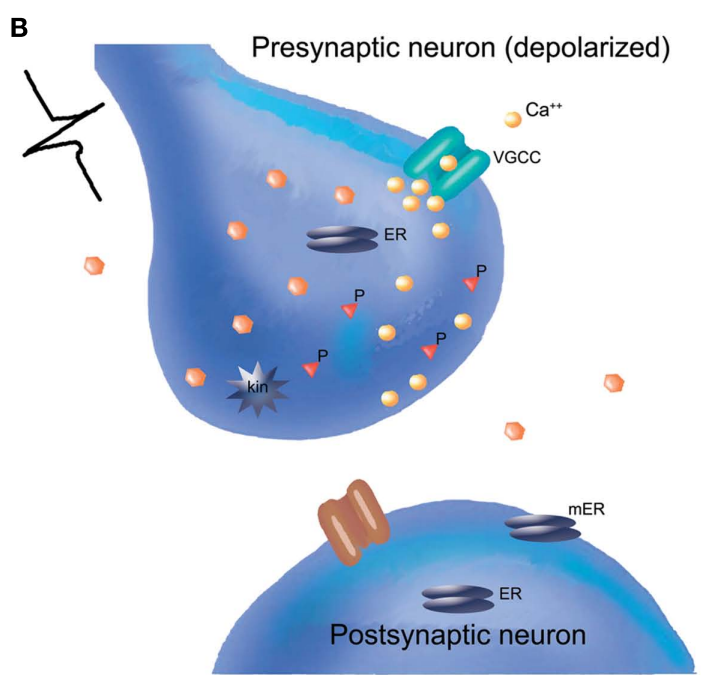

(mER; gray ovals, membrane-bound). Synaptocrine estrogens may therefore modulate post-synaptic neurotransmitter receptors and/or have genomic effects on the post-synaptic cell. These scenarios are most likely to occur when the cell membrane is at rest (i.e., not depolarized) and when voltage-gated calcium channels (VGCCs) are closed. In contrast, (right panel), depolarization of the synaptic neuron and concomitant $\mathrm{Ca} 2+$ influx into the presynaptic bouton may activate a calcium-dependent kinase (kin), phosphorylate presynaptic aromatase (P), and thereby decrease synaptocrine estrogen synthesis, while simultaneously potentially increasing the local concentration of androgens. 
and typically consist of either messenger degradation (such as in the case of acetylcholine) or messenger reuptake (such as in the case for serotonin). In the case of synaptocrine steroid production, it is currently unknown what mechanisms could allow for the spatiotemporal fidelity of steroids produced at the synapse. Several candidate mechanisms include: (1) rapid hydroxylation by enzymes to increase the aqueous solubility of steroids and thereby aid in clearance and decrease their potency (Do Rego et al., 2009); (2) steroid conjugation, in which sulfate and glucuronide groups are added to possibly inactivate steroids within the brain (Jantti et al., 2010); and (3) constitutive mechanisms to sequester synaptocrine steroids via binding proteins such as sex-steroid binding globulin (Caldwell et al., 2006) or even alpha-fetoprotein (Mcleod and Cooke, 1989), which would be predicted to be located at or near the synaptic cleft. Therefore, there are candidate mechanisms to account for the sequestration of steroids produced via synaptocrine secretion, but it remains unknown whether these mechanisms operate at the acute spatial and temporal scale to provide the fidelity match required for reliable information transfer that is a hallmark of classical neuromodulators.

\section{CONCLUSION}

Although our focus here is on estrogen signaling in the songbird brain, there is a growing body of evidence showing that steroidal synaptocrine signaling could be conserved across vertebrates and across brain regions (Remage-Healey and Bass, 2006; Hojo et al., 2008; Srivastava et al., 2010). Moreover, whereas neural estrogen actions are widely studied, especially their rapid membrane actions, other neuroactive steroids are likely formed presynaptically (e.g., Majewska, 1992; Tsutsui et al., 2004, 2010) thereby functioning also as targeted synaptocrine signals. The subcellular localization of enzymes required to synthesize neuroactive steroids merits further investigation.

Steroids synthesized in the presynaptic bouton are just as likely to exert presynaptic as post-synaptic effects. Indeed, receptors for both estrogens (Mitterling et al., 2010; Waters et al., 2011) and androgens (Tabori et al., 2005) have been documented

\section{REFERENCES}

Adkins, E. K., and Adler, N. T. (1972). Hormonal control of behavior in the Japanese quail. J. Comp. Physiol. Psychol. 81, 27-36.

Adkins Regan, E. (1981). Effect of sex steroids on the reproductivebehavior of castrated male Ring Doves (Streptopelia-Sp). Physiol. Behav. 26, 561-565.

Adkins-Regan, E., Abdelnabi, M., Mobarak, M., and Ottinger, M. A. (1990). Sex steroid levels in developing and adult male and female zebra finches (Poephila guttata). Gen. Comp. Endocrinol. 78, 93-109.

Arnold, A. P., and Schlinger, B. A. (1993). Sexual-differentiation of brain and behavior - the zebra finch is not just a flying rat. Brain Behav. Evol. 42, 231-241.
Ball, G. F., and Balthazart, J. (2002). "Neuroendocrine mechanisms regulating reproductive cycles and reproductive behavior in birds," in Hormones, Bran and Behavior, ed. D. W. Pfaff (Amsterdam: Academic Press), 649-798.

Balthazart, J., Foidart, A., Surlemont, C., Vockel, A., and Harada, N. (1990). Distribution of aromatase in the brain of the Japanese quail, ring dove, and zebra finch: an immunocytochemical study. J. Comp. Neurol. 301, 276-288.

Balthazart, J. (1990). Brain aromatization of testosterone regulates male reproductive behavior in birds. Prog. Clin. Biol. Res. 342, 92-98.

Balthazart, J., Absil, P., Foidart, A., Houbart, M., Harada, N., and Ball, G. F. (1996). Distribution of aromatase-immunoreactive cells

within presynaptic boutons of the rodent brain and in the zebra finch HVC (Saldanha, unpublished observations). Synaptocrine steroids could interact with their cognate receptors within the presynaptic boutons and thereby affect presynaptic function (Saldanha et al., 2004). For example, estrogens can rapidly potentiate the excitability of rodent hippocampal neurons via a presynaptic mechanism (Smejkalova and Woolley, 2010), perhaps via receptors located on the walls of neurotransmitter vesicles (Hart et al., 2007). Given these data, estrogens synthesized within the presynaptic bouton may alter the probability of neurotransmitter release, thereby affecting synaptic information transfer.

Irrespective of the pre- or post-synaptic site of action, secretion of neuroactive steroids locally and acutely at the synapse represents a conceptually new frontier for neuroendocrinology (Figure 2). Here, and in a more detailed review (Saldanha et al., 2011) we present the concept of synaptocrinology as a new way of considering how steroids are delivered spatially and temporally to discrete neural circuits. Yet these ideas do not apply to steroids alone, as other lipophilic neuromodulators may have similar anatomical and physiological specializations for actions in the CNS. Alongside future studies of steroid synaptocrinology, it will be fascinating to explore whether similar mechanisms exist for other lipophilic modulators, such as thyroxine or endocannabinoids. Indeed, thyroid hormones can exert non-genomic effects in the CNS (Davis et al., 2008; Caria et al., 2009), are synthesized in bouton-like beads along processes throughout rat cortex (Rozanov and Dratman, 1996), and have been previously proposed as neurotransmitters (Dratman and Gordon, 1996). Thus, a focus on synaptocrinology will likely continue to bear fruit in the field of neurosteroids and beyond.

\section{ACKNOWLEDGMENTS}

This work was supported by the National Institutes of Health (GrantsF32NS058009, R01MH061944, RO1NS042767 and K99/R00NS066179).

in the forebrain of zebra finches (Taeniopygia guttata): implications for the neural action of steroids and nuclear definition in the avian hypothalamus. J. Neurobiol. 31, 129-148.

Balthazart, J., Baillien, M., and Ball, G. (2001). Rapid and reversible inhibition of brain aromatase activity. $J$. Neuroendocrinol. 13, 63-73.

Balthazart, J., Baillien, M., and Ball, G. F. (2006). Rapid control of brain aromatase activity by glutamatergic inputs. Endocrinology 147, 359-366.

Balthazart, J., Baillien, M., Charlier, T., and Ball, G. (2003). Calcium-dependent phosphorylation processes control brain aromatase in quail. Eur. J. Neurosci. 17, 1591-1606.

Balthazart, J., Baillien, M., Charlier, T., and Ball, G. (2005). Effects of calmodulin on aromatase activity in the preoptic area. J. Neuroendocrinol. 17, 664-671.

Balthazart, J., Baillien, M., Cornil, C. A., and Ball, G. F. (2004). Preoptic aromatase modulates male sexual behavior: slow and fast mechanisms of action. Physiol. Behav. 83, 247-270.

Balthazart, J., and Ball, G. F. (2006). Is brain estradiol a hormone or a neurotransmitter? Trends Neurosci. 29, 241-249.

Baulieu, E. E., and Robel, P. (1990). Neurosteroids - a new brain-function. J. Steroid Biochem. Mol. Biol. 37, 395-403.

Beyer, C., Pawlak, J., and Karolczak, M. (2003). Membrane receptors for oestrogen in the brain. J. Neurochem. 87, 545-550. 
Blaustein, J. D. (1992). Cytoplasmic estrogen receptors in rat brain: immunocytochemical evidence using three antibodies with distinct epitopes. Endocrinology 131, 1336-1342.

Blaustein, J. D., Lehman, M. N., Turcotte, J. C., and Greene, G. (1992). Estrogen-receptors in dendrites and axon terminals in the guinea-pig hypothalamus. Endocrinology 131, 281-290.

Bolhuis, J. J., and Gahr, M. (2006). Neural mechanisms of birdsong memory. Nat. Rev. Neurosci. 7, 347-357.

Bottjer, S. W., and Johnson, F. (1997). Circuits, hormones, and learning: vocal behavior in songbirds. J. Neurobiol. 33, 602-618.

Caldwell, J. D., Suleman, F., Chou, S. H., Shapiro, R. A., Herbert, Z., and Jirikowski, G. F. (2006). Emerging roles of steroid-binding globulins. Horm. Metab. Res. 38, 206-218.

Callard, G. V. (1984). "Aromatization in brain and pituitary: an evolutionary perspective," in Metabolism of Hormonal Steroids in the Neuroendocrine Structures, eds F. Celotti, F. Naftolin, L. Martini (New York: Raven Press), 79-102.

Callard, G. V., Petro, Z., and Ryan, K. J. (1978). Phylogenetic distribution of aromatase and other androgen-converting enzymes in the central nervous system. Endocrinology 103, 2283-2290.

Canick, J. A., Vaccaro, D. E., Livingston, E. M., Leeman, S. E., Ryan, K. J., and Fox, T. O. (1986). Localization of aromatase and $5 \alpha$-eductase to neuronal and non-neuronal cells in the fetal rat hypothalamus. Brain Res. $372,277-282$.

Caria, M. A., Dratman, M. B., Kow, L. M., Mameli, O., and Pavlides, C. (2009). Thyroid hormone action: nongenomic modulation of neuronal excitability in the hippocampus. J. Neuroendocrinol. 21, 98-107.

Carlisle, H. J., Hales, T. G., and Schlinger, B. A. (1998). Characterization of neuronal zebra finch GABA(A) receptors: steroid effects. J. Comp. Physiol. 182, 531-538.

Clayton, N. (2002). Brain, perception, memory: advances in cognitive neuroscience. Q. J. Exp. Psychol. B 55, 191-192.

Compagnone, N. A., Bulfone, A., Rubenstein, J. L., and Mellon, S. H. (1995a). Expression of the steroidogenic enzyme P450scc in the central and peripheral nervous systems during rodent embryogenesis. Endocrinology 136, 2689-2696.

Compagnone, N. A., Bulfone, A., Rubenstein, J. L., and Mellon, S. H. (1995b). Steroidogenic enzyme $\mathrm{P} 450 \mathrm{c} 17$ is expressed in the embryonic central nervous system. Endocrinology 136, 5212-5223.

Cornil, C. A. (2009). Rapid regulation of brain oestrogen synthesis: the behavioural roles of oestrogens and their fates. J. Neuroendocrinol. 21, 217-226.

Davis, P. J., Leonard, J. L., and Davis, F. B. (2008). Mechanisms of nongenomic actions of thyroid hormone. Front. Neuroendocrinol. 29, 211-218.

Do Rego, J. L., Seong, J. Y., Burel, D., Leprince, J., Luu-The, V., Tsutsui, K., Tonon, M. C., Pelletier, G., and Vaudry, H. (2009). Neurosteroid biosynthesis: enzymatic pathways and neuroendocrine regulation by neurotransmitters and neuropeptides. Front. Neuroendocrinol. 30, 259-301.

Dratman, M. B., and Gordon, J. T (1996). Thyroid hormones as neurotransmitters. Thyroid 6, 639-647.

Foidart, A., Harada, N., and Balthazart, J. (1994). Effects of steroidal and non steroidal aromatase inhibitors on sexual behavior and aromatase immunoreactive cells and fibers in the quail brain. Brain Res. 657, 105-123.

Forlano, P. M., Deitcher, D. L., Myers, D. A., and Bass, A. H. (2001). Anatomical distribution and cellular basis for high levels of aromatase activity in the brain of teleost fish: aromatase enzyme and mRNA expression identify glia as source. J. Neurosci. 21, 8943-8955.

Forlano, P. M., Schlinger, B. A., and Bass, A. H. (2006). Brain aromatase: new lessons from nonmammalian model systems. Front. Neuroendocrinol. 27, 247-274.

Fusani, L., Hutchison, J. B., and Gahr, M. (2001). Testosterone regulates the activity and expression of aromatase in the canary neostriatum. $J$. Neurobiol. 49, 1-8.

Fusani, L., Van't Hof, T., and Hutchison, J. B. (2003). Season-related changes in circulating androgen, brain aromatase, and perch-calling in male ring doves. Gen. Comp. Endocrinol. 130, 142-147.

Grisham, W., Lee, J., Park, S. H., Mankowski, J. L., and Arnold, A. P. (2008). A dose-response study of estradiol's effects on the developing zebra finch song system. Neurosci. Lett. 445, 158-161.

Gurney, M., and Konishi, M. (1980). Hormone-induced sexual differentiation of brain and behavior in zebra finches. Science 208, 1380-1383.

Hart, S. A., Snyder, M. A., Smejkalova, T., and Woolley, C. S. (2007). Estrogen mobilizes a subset of estrogen receptor-alpha-immunoreactive vesicles in inhibitory presynaptic boutons in hippocampal CAl. $J$. Neurosci. 27, 2102-2111.

Hojo, Y., Hattori, T. A., Enami, T. Furukawa, A., Suzuki, K., Ishii, H. T. Mukai, H., Morrison, J. H., Janssen, W. G., Kominami, S., Harada, N. Kimoto, T., and Kawato, S. (2004). Adult male rat hippocampus synthesizes estradiol from pregnenolone by cytochromes P45017alpha and P450 aromatase localized in neurons. Proc. Natl. Acad. Sci. U.S.A. $101,865-870$

Hojo, Y., Murakami, G., Mukai, H., Higo, S., Hatanake, Y., Ogiue-Ikeda, M., Ishii, H., Kimotot, T., and Kawato, S. (2008). Estrogen synthesis in the brain-role in synaptic plasticity and memory. Mol. Cell. Endocrinol. 290, 31-43.

Horvath, T. L., Roa-Pena, L., Jakab, R. L., Simpson, E. R., and Naftolin, F. (1997). Aromatase in axonal processes of early postnatal hypothalamic and limbic areas including the cingulate cortex. J. Steroid Biochem. Mol. Biol. 61, 349-357.

Hutchison, J. B., and Steimer, T. (1981). Brain 5?-reductase - a correlate of behavioral sensitivity to androgen. Science 213, 244-246.

Hutchison, J. B., Wingfield, J. C., and Hutchison, R. E. (1984). Sex differences in plasma concentrations of steroids during the sensitive period for brain differentiation in the zebra finch. J. Endocrinol. 103, 363-369.

Immelman, K. (1969). "Song development in the zebra finch and other estrildid finches," in Bird Vocalizations, ed. R. Hinde (Cambridge: Cambridge University Press), 61-74.

Jantti, S. E., Tammimaki, A., Raattamaa, H., Piepponen, P., Kostiainen, R. and Ketola, R. A. (2010). Determination of steroids and their intact glucuronide conjugates in mouse brain by capillary liquid chromatographytandem mass spectrometry. Anal. Chem. 82, 3168-3175.

Katz, P. S. (ed.). (1999). Beyond Neurotransmission. New York: Oxford University Press.

King, S. R., Manna, P. R., Ishii, T., Syapin, P. J., Ginsberg, S. D., Wilson, K., Walsh, L. P., Parker, K. L., Stocco, D. M., Smith, R. G., and Lamb, D. J. (2002). An essential component in steroid synthesis, the steroidogenic acute regulatory protein, is expressed in discrete regions of the brain. $J$. Neurosci. 22, 10613-10620.

Konishi, M., Emlen, S. T., Ricklefs, R. E., and Wingfield, J. C. (1989). Contributions of bird studies to biology. Science 246, 465-472.

Kretz, O., Fester, L., Wehrenberg, U., Zhou, L., Brauckmann, S., Zhao, S. Prange-Kiel, J., Naumann, T., Jarry, H., Frotscher, M., and Rune, G.
M. (2004). Hippocampal synapses depend on hippocampal estrogen synthesis. J. Neurosci. 24, 5913-5921.

Lan, N. C., and Gee, K. W. (1994). Neuroactive steroid actions at the GABAA receptor. Horm. Behav. 28, 537-544.

Lephart, E. D. (1996). A review of brain aromatase cytochrome P450. Brain Res. Rev. 22, 1-26.

Loewi, O. (1921). Uber humorale Ubertragbarkeit der Herznervenwirkung. Pflugers Arch. 189:239-242.

London, S., Monks, D. A., Wade, J., and Schlinger, B. A. (2006). Widespread capacity for steroid synthesis in the avian brain and song system. Endocrinology 147, 5975-5987.

London, S., and Schlinger, B. A. (2007). Steroidogenic enzymes along the ventricular proliferative zone in the developing songbird brain. J. Comp. Neurol. 502, 507-521.

London, S. E., Boulter, J., and Schlinger, B. A. (2003). Cloning of the zebra finch androgen synthetic enzyme CYP17: a study of its neural expression throughout posthatch development. J. Comp. Neurol. 467, 496-508.

London, S. E., Itoh, Y., Lance, V. A., Wise, P. M., Ekanayake, P. S., Oyama, R. K., Arnold, A. P., and Schlinger, B. A. (2010). Neural expression and posttranscriptional dosage compensation of the steroid metabolic enzyme 17beta-HSD type 4. BMC Neurosci. 11, 47. doi: 10.1186/1471-2202-1147

London, S. E., Remage-Healey, L., and Schlinger, B. A. (2009). Neurosteroid production in the songbird brain: a re-evaluation of core principles. Front. Neuroendocrinol. 30, 302-314.

Maclusky, N. J., and Naftolin, F. (1981). Sexual differentiation of the central nervous system. Science 211, 1294-1302.

Majewska, M. D. (1992). Neurosteroids: endogenous bimodal modulators of the GABAA receptor. Mechanism of action and physiological significance. Prog. Neurobiol. 38, 379-395.

Majewska, M. D., Harrison, N. L., Schwartz, R. D., Barker, J. L., and Paul, S. M. (1986). Steroid-hormone metabolites are barbiturate-like modulators of the gaba receptor. Science 232, 1004-1007.

Martini, L. (1982). The 5alphareduction of testosterone in the neuroendocrine structures. Biochemical and biophysical implications. Endocr. Rev. 3, 1-25.

Mcewen, B. S. (1981). Neural gonadal steroid actions. Science 211, 1303-1311.

Mcewen, B. S., and Alves, S. E. (1999). Estrogen actions in the central nervous system. Endocr. Rev. 20, 279-307. 
Mcleod, J. F., and Cooke, N. E. (1989). The vitamin D-binding protein, alpha-fetoprotein, albumin multigene family: detection of transcripts in multiple tissues. J. Biol. Chem. 264, 21760-21769.

Meitzen, J., and Mermelstein, P. G. (2011). Estrogen receptors stimulate brain region specific metabotropic glutamate receptors to rapidly initiate signal transduction pathways. $J$. Chem. Neuroanat. PMID: 21458561. [Epub ahead of print].

Meitzen, J., Moore, I. T., Lent, K., Brenowitz, E. A., and Perkel, D. J. (2007). Steroid hormones act transsynaptically within the forebrain to regulate neuronal phenotype and song stereotypy. J. Neurosci. 27, 12045-12057.

Mermelstein, P. G., Becker, J. B., and Surmeier, D. J. (1996). Estradiol reduces calcium currents in rat neostriatal neurons via a membrane receptor. J. Neurosci. 16, 595-604.

Micevych, P. E., and Mermelstein, P. G. (2008). Membrane estrogen receptors acting through metabotropic glutamate receptors: an emerging mechanism of estrogen action in brain. Mol. Neurobiol. 38, 66-77.

Miller, W. L. (1988). Molecular biology of steroid hormone synthesis. Endocr. Rev. 9, 295-318.

Milner, T. A., Mcewen, B. S., Hayashi, S., Li, C. J., Reagan, L. P., and Alves, S. E. (2001). Ultrastructural evidence that hippocampal alpha estrogen receptors are located at extranuclear sites. J. Comp. Neurol. 429, 355-371.

Mitterling, K. L., Spencer, J. L., Dziedzic, N., Shenoy, S., Mccarthy, K., Waters, E. M., Mcewen, B. S., and Milner, T. A. (2010). Cellular and subcellular localization of estrogen and progestin receptor immunoreactivities in the mouse hippocampus. J. Comp. Neurol. 518, 2729-2743.

Moenter, S. M., and Chu, Z. (2011). Rapid non-genomic effects of oestradiol on GnRH neurons. J. Neuroendocrinol. doi: 10.1111/j.1365-2826.2011.02135.x. [Epub ahead of print].

Montague, D., Weickert, C. S., Tomaskovic-Crook, E., Rothmond, D. A., Kleinman, J. E., and Rubinow, D. R. (2008). Oestrogen receptor alpha localisation in the prefrontal cortex of three mammalian species. J. Neuroendocrinol. 20, 893-903.

Mooney, R. (2009). Neurobiology of song learning. Curr. Opin. Neurobiol. 19, 654-660.

Mukai, H., Takata, N., Ishii, H. T., Tanabe, N., Hojo, Y., Furukawa, A.,
Kimoto, T., and Kawato, S. (2006). Hippocampal synthesis of estrogens and androgens which are paracrine modulators of synaptic plasticity: synaptocrinology. Neuroscience 138 , 757-764.

Murakami, G., Tanabe, N., Ishii, H. T., Ogiue-Ikeda, M., Tsurugizawa, T., Mukai, H., Hojo, Y., Takata, N., Furukawa, A., Kimoto, T., and Kawato, S. (2006). Role of cytochrome P450 in synaptocrinology: endogenous estrogen synthesis in the brain hippocampus. Drug Metab. Rev. 38, 353-369.

Naftolin, F., Horvath, T. L., Jakab, R. L., Leranth, C., Harada, N., and Balthazart, J. (1996). Aromatase immunoreactivity in axon terminals of the vertebrate brain. An immunocytochemical study on quail, rat, monkey and human tissues. Neuroendocrinology 63, 149-155.

Naftolin, F., Ryan, K. J., Davies, I. J., Reddy, V. V., Flores, F., Petro, Z., Kuhn, M., White, R. J., Takaoka, Y., and Wolin, L. (1975). The formation of estrogens by central neuroendocrine tissues. Rec. Prog. Horm. Res. 31, 295-319.

Naftolin, F., Ryan, K. J., and Petro, Z. (1971). Aromatization of androstenedione by limbic system tissue from human foetuses. J. Endocrinol. 51, 795-796.

Nottebohm, F., and Arnold, A. P. (1976). Sexual dimorphism in vocal control areas of the songbird brain. Science 194, 211-213.

Nottebohm, F., Stokes, T. M., and Leonard, C. M. (1976). Central control of song in the canary, Serinus canarius. J. Comp. Neurol. 165, 457-486.

Oberlander, J. G., Schlinger, B. A., Clayton, N. S., and Saldanha, C. J. (2004). Neural aromatization accelerates the acquisition of spatial memory via an influence on the songbird hippocampus. Horm. Behav. 45, 250-258.

Pasmanik, M., Schlinger, B. A., and Callard, G. V. (1988). In vivo steroid regulation of aromatase and $5 \alpha$ reductase in goldfish brain and pituitary. Gen. Comp. Endocrinol. 71, 175-182.

Payne, A. H., and Hales, D. B. (2004). Overview of steroidogenic enzymes in the pathway from cholesterol to active steroid hormones. Endocr. Rev. 25, 947-970.

Peterson, R. S., Yarram, L., Schlinger, B. A., and Saldanha, C. J. (2005). Aromatase is pre-synaptic and sexually dimorphic in the adult zebra finch brain. Proc. R. Soc. B Biol. Sci. 272, 2089-2096.
Portillo, W., Castillo, C. G., RetanaMarquez, S., Roselli, C. E., and Paredes, R. G. (2007). Neuronal activity of aromatase enzyme in noncopulating male rats. J. Neuroendocrinol. 19, 139-141.

Pradhan, D. S., Newman, A. E., Wacker, D. W., Wingfield, J. C., Schlinger, B. A., and Soma, K. K. (2010). Aggressive interactions rapidly increase androgen synthesis in the brain during the non-breeding season. Horm. Behav. 57, 381-389.

Prange-Kiel, J., and Rune, G. M. (2006). Direct and indirect effects of estrogen on rat hippocampus. Neuroscience 138, 765-772.

Reddy, D. S. (2010). Neurosteroids: endogenous role in the human brain and therapeutic potentials. Prog. Brain Res. 186, 113-137.

Remage-Healey, L., and Bass, A. H. (2006). A rapid neuromodulatory role for steroid hormones in the control of reproductive behavior. Brain Res. 1126, 27-35.

Remage-Healey, L., Coleman, M. J., Oyama, R. K., and Schlinger, B. A. (2010a). Brain estrogens rapidly strengthen auditory encoding and guide song preference in a songbird. Proc. Natl. Acad. Sci. U.S.A. 107, 3852-3857.

Remage-Healey, L., London, S. E., and Schlinger, B. A. (2010b). Birdsong and the neural production of steroids. J. Chem. Neuroanat. 39, 72-81.

Remage-Healey, L., Dong, S., Maidment, N. T., and Schlinger, B. A (2011). Presynaptic control of rapid estrogen fluctuations in the songbird auditory forebrain. J. Neurosci. 31, 10034-10038.

Remage-Healey, L., Maidment, N. T., and Schlinger, B. A. (2008). Forebrain steroid levels fluctuate rapidly during social interactions. Nat. Neurosci. 11, 1327-1334.

Remage-Healey, L., Oyama, R. K., and Schlinger, B. A. (2009). Elevated aromatase activity in forebrain synaptic terminals during song. J. Neuroendocrinol. 21, 191-199.

Riters, L., Baillien, M., Eens, M., Pinxten, R., Foidart, A., Ball, G., and Balthazart, J. (2001). Seasonal variation in androgen-metabolizing enzymes in the diencephalon and telencephalon of the male European starling (Sturnus vulgaris). J. Neuroendocrinol. 13 , 985-997.

Roepke, T. A., Ronnekleiv, O. K., and Kelly, M. J. (2011). Physiological consequences of membraneinitiated estrogen signaling in the brain. Front. Biosci. 16, 1560-1573.

Rohmann, K. N., Schlinger, B. A., and Saldanha, C. J. (2007). Subcellular compartmentalization of aromatase is sexually dimorphic in the adult zebra finch brain. Dev. Neurobiol. 67 $1-9$.

Roselli, C. E. (1991). Synergistic induction of aromatase-activity in the rat-brain by estradiol and $5 \alpha$-dihydrotestosterone. Neuroendocrinology 53, 79-84.

Roselli, C. E., Cross, E., Poonyagariyagorn, H. K., and Stadelman, H. L. (2003). Role of aromatization in anticipatory and consummatory aspects of sexual behavior in male rats. Horm. Behav. 44, 146-151.

Roselli, C. E., and Resko, J. A. (2001). Cytochrome P450 aromatase (CYP19) in the non-human primate brain: distribution, regulation, and functional significance. J. Steroid Biochem. Mol. Biol. 79, 247-253.

Rozanov, C. B., and Dratman, M. B. (1996). Immunohistochemical mapping of brain triiodothyronine reveals prominent localization in central noradrenergic systems. $\mathrm{Neu}$ roscience 74, 897-915.

Saldanha, C. J., and Coomaralingam, L. (2005). Overlap and co-expression of estrogen synthetic and responsive neurons in the songbird brain - a double-label immunocytochemical study. Gen. Comp. Endocrinol. 141, 66-75.

Saldanha, C. J., Duncan, K. A., and Walters, B. J. (2009). Neuroprotective actions of brain aromatase. Front. Neuroendocrinol. 30, 106-118.

Saldanha, C. J., Peterson, R. S., Yarram, L., and Schlinger, B. A. (2003). The synaptocrine hypothesis: a novel form of estrogen delivery. Abstr. Soc. Neurosci. Abstract 610.14

Saldanha, C. J., Popper, P., Micevych, P. E., and Schlinger, B. A. (1998). The passerine hippocampus is a site of high aromatase: inter- and intraspecies comparisons. Horm. Behav. 34, 85-97.

Saldanha, C. J., Remage-Healey, L., and Schlinger, B. A. (2011). Synaptocrine signaling: steroid synthesis and action at the synapse. Endocr. Rev. 32, 532-549.

Saldanha, C. J., and Schlinger, B. A. (1997). Estrogen synthesis and secretion in the brown-headed cowbird (Molothrus ater). Gen. Comp. Endocrinol. 105, 390-401.

Saldanha, C. J., and Schlinger, B. A. (2008). "Steroidogenesis and neuroplasticity in the songbird brain," in Neuroactive Steroids in Brain Function, Behavioral and Neuropsychiatric Disorders. Novel Strategies for Research and Treatment, eds M. S. Ritsner and A. Weizman (Pondicherry: Springer), 201-218. 
Saldanha, C. J., Schlinger, B. A., Micevych, P. E., and Horvath, T. L. (2004). Presynaptic N-methylD-aspartate receptor expression is increased by estrogen in an aromatase-rich area of the songbird hippocampus. J. Comp. Neurol. 469, 522-534.

Saldanha, C. J., Tuerk, M. J., Kim, Y. H., Fernandes, A. O., Arnold, A. P., and Schlinger, B. A. (2000). Distribution and regulation of telencephalic aromatase expression in the zebra finch revealed with a specific antibody. J. Comp. Neurol. 423 , 619-630.

Santen, R. J., Brodie, H., Simpson, E. R., Siiteri, P. K., and Brodie, A. (2009). History of aromatase: saga of an important biological mediator and therapeutic target. Endocr. Rev. 30, 343-375.

Scharrer, E. (1954). Neurosecretion and anterior pituitary in the dog. Experientia 10, 264-266.

Schlinger, B. A., Amur-Umarjee, S., Campagnoni, A. T., and Arnold, A. P. (1995). $5 \beta$-reductase and other androgen-metabolizing enzymes in primary cultures of developing zebra finch telencephalon. J. Neuroendocrinol. 7, 187-192.

Schlinger, B. A., and Arnold, A. P. (1991). Brain is the major site of estrogen synthesis in a male songbird. Proc. Natl. Acad. Sci. U.S.A. 88, 4191-4194.

Schlinger, B. A., and Arnold, A. P. (1992a). Circulating estrogens in a male songbird originate in the brain. Proc. Natl. Acad. Sci. U.S.A. 89, 7650-7653.

Schlinger, B. A., and Arnold, A. P. (1992b). Plasma sex steroids and tissue aromatization in hatchling zebra finches: implications for the sexual differentiation of singing behavior. Endocrinology 130, 289-299.

Schlinger, B. A., and Callard, G. V. (1989a). Estrogen receptors in quail brain: a functional relationship to aromatase and aggressiveness. Biol. Reprod. 40, 268-275.

Schlinger, B. A., and Callard, G. V. (1989b). Localization of aromatase in synaptosomal and microsomal subfractions of quail (Coturnix coturnix japonica) brain. Neuroendocrinology 49, 434-441.

Schlinger, B. A., Slotow, R. H., and Arnold, A. P. (1992). Plasma estrogens and brain aromatase in winter white-crowned sparrows. Ornis Scand. 23, 292-297.

Shen, P., Campagnoni, C. W., Kampf, K., Schlinger, B. A., Arnold, A. P., and Campagnoni, A. T. (1994). Isolation and characterization of a zebra finch aromatase cDNA - in situ hybridization reveals high aromatase expression in brain. Mol. Brain Res. 24, 227-237.

Shen, P., Schlinger, B. A., Campagnoni, A. T., and Arnold, A. P. (1995). An atlas of aromatase mRNA expression in the zebra finch brain. J. Comp. Neurol. 360, 172-184.

Silverin, B., Baillien, M., Foidart, A., and Balthazart, J. (2000). Distribution of aromatase activity in the brain and peripheral tissues of passerine and nonpasserine avian species. Gen. Comp. Endocrinol. 117, 34-53.

Simpson, E. R., Clyne, C., Rubin, G., Boon, W. C., Robertson, K., Britt, K., Speed, C., and Jones, M. (2002). Aromatase - a brief overview. Annu. Rev. Physiol. 64, 93-127.

Simpson, H. B., and Vicario, D. S. (1991). Early estrogen treatment of female zebra finches masculinizes the brain pathway for learned vocalizations. J. Neurobiol. 22, 777-793.

Smejkalova, T., and Woolley, C. S. (2010). Estradiol acutely potentiates hippocampal excitatory synaptic transmission through a presynaptic mechanism. J. Neurosci. 30, 16137-16148.

Snyder, S. H. (2009). Neurotransmitters, receptors, and second messengers galore in 40 years. J. Neurosci. 29, 12717-12721.

Soma, K. K., Bindra, R.K., Gee, J., Wingfield, J., and Schlinger, B. A. (1999). Androgen metabolizing enzymes show region-specific changes across the breeding season in the brain of a wild breeding song bird. J. Neurobiol. 41, 176-188.

Soma, K. K., Schlinger, B. A., Wingfield, J. C., and Saldanha, C. J. (2003). Brain aromatase, $5 \alpha$-reductase, and $5 \beta$-reductase change seasonally in wild male song sparrows: relationship to aggressive and sexual behavior. J. Neurobiol. 56, 209-221.

Soma, K. K., and Wingfield, J. C. (2001). Dehydroepiandrosterone in songbird plasma: seasonal regulation and relationship to territorial aggression. Gen. Comp. Endocrinol. 123, 144-155.

Soma, K. K., Wissman, A. M., Brenowitz, E. A., and Wingfield, J. C. (2002) Dehydroepiandrosterone (DHEA) increases territorial song and the size of an associated brain region in a male songbird. Horm. Behav. 41, 203-212.

Srivastava, D. P., Woolfrey, K. M., Liu, F., Brandon, N. J., and Penzes, P. (2010). Estrogen receptor ss activity modulates synaptic signaling and structure. J. Neurosci. 30, 13454-13460.
Szego, C. M., and Davis, J. S. (1967) Adenosine $3^{\prime}, 5^{\prime}$-monophosphate in rat uterus: acute elevation by estrogen. Proc. Natl. Acad. Sci. U.S.A. 58, 1711-1718.

Szekely, A. D., and Krebs, J. R. (1996). Efferent connectivity of the hippocampal formation of the zebra finch (Taenopygia guttata): an anterograde pathway tracing study using Phaseolus vulgaris leucoagglutinin. J. Comp. Neurol. 368 198-214.

Tabori, N. E., Stewart, L. S., Znamensky, V., Romeo, R. D., Alves, S. E., Mcewen, B. S., and Milner, T. A. (2005). Ultrastructural evidence that androgen receptors are located at extranuclear sites in the rat hippocampal formation. Neuroscience 130, 151-163.

Tam, H., and Schlinger, B. A. (2007) Activities of $3 \beta$-HSD and aromatase in slices of the adult and developing zebra finch brain. Gen. Comp. Endocrinol. 150, 26-33.

Tramontin, A. D., Wingfield, J. C., and Brenowitz, E. A. (2003). Androgens and estrogens induce seasonallike growth of song nuclei in the adult songbird brain. J. Neurobiol. 57, 130-140.

Tremere, L. A., Jeong, J. K., and Pinaud, R. (2009). Estradiol shapes auditory processing in the adult brain by regulating inhibitory transmission and plasticity-associated gene expression. J. Neurosci. 29, 5949-5963.

Tremere, L. A., and Pinaud, R. (2011). Brain-generated estradiol drives long-term optimization of auditory coding to enhance the discrimination of communication signals. J. Neurosci. 31, 3271-3289.

Tsutsui, K., Haraguchi, S., Matsunaga, M., Koyama, T., Do Rego, J. L., and Vaudry, H. (2010). Identification of $7 \alpha$-hydroxypregnenolone, a novel bioactive amphibian neurosteroid stimulating locomotor activity, and its physiological roles in the regulation of locomotion. Gen. Comp. Endocrinol. 168, 275-279.

Tsutsui, K., Matsunaga, M., Miyabara, H., and Ukena, K. (2004). Identification and mode of action of a novel neurosteroid stimulating locomotor activity. Zool. Sci. 21, 1201-1202.

Vanson, A., Arnold, A. P., and Schlinger, B. A. (1996). 3 $\beta$-hydroxysteroid dehydrogenase/isomerase and aromatase activity in primary cultures of developing zebra finch telencephalon: dehydroepiandrosterone as substrate for synthesis of androstenedione and estrogens. Gen. Comp. Endocrinol. 102, 342-350.
Vockel, A., Pröve, E., and Balthazart, J. (1990a). Effects of castration and testosterone treatment on the activity of testosteronemetabolizing enzymes in the brain of male and female zebra finches. $J$. Neurobiol. 21, 808-825.

Vockel, A., Pröve, E., and Balthazart, J. (1990b). Sex- and age-related differences in the activity of testosteronemetabolizing enzymes in microdissected nuclei of the zebra finch brain. Brain Res. 511, 291-302.

Wade, J., Schlinger, B. A., and Arnold, A. P. (1995). Aromatase and $5 \alpha$-reductase activity in cultures of developing zebra finch brain: an Investigation of sex and regional differences. J. Neurobiol. 27, 240-251.

Waters, E. M., Yildirim, M., Janssen, W. G., Lou, W. Y., Mcewen, B. S. Morrison, J. H., and Milner, T. A (2011). Estrogen and aging affect the synaptic distribution of estrogen receptor $\beta$-immunoreactivity in the CA1 region of female rat hippocampus. Brain Res. 1379, 86-97.

Woolley, C. S. (2007). Acute effects of estrogen on neuronal physiology. Annu. Rev. Pharmacol. Toxicol. 47, 657-680.

Wu, M. V., Manoli, D. S., Fraser, E. J., Coats, J. K., Tollkuhn, J., Honda, S., Harada, N., and Shah, N. M. (2009). Estrogen masculinizes neural pathways and sex-specific behaviors. Cell 139, 61-72.

Conflict of Interest Statement: The authors declare that the research was conducted in the absence of any commercial or financial relationships that could be construed as a potential conflict of interest.

Received: 07 July 2011; paper pending published: 28 July 2011; accepted: 26 August 2011; published online: 29 September 2011.

Citation: Remage-Healey L, Saldanha CJ and Schlinger BA (2011) Estradiol synthesis and action at the synapse: evidence for "synaptocrine" signaling. Front. Endocrin. 2:28. doi: 10.3389/fendo.2011.00028

This article was submitted to Frontiers in Neuroendocrine Science, a specialty of Frontiers in Endocrinology.

Copyright (c) 2011 Remage-Healey, Saldanha and Schlinger. This is an openaccess article subject to a non-exclusive license between the authors and Frontiers Media SA, which permits use, distribution and reproduction in other forums, provided the original authors and source are credited and other Frontiers conditions are complied with. 